\title{
Efeitos macroeconômicos da seguridade social num contexto de bônus demográfico: simulação de um modelo do ciclo da vida
}

\author{
Henrique Reichert ${ }^{*}$ \\ Patricia Bonini ${ }^{\star *}$ \\ Carolina Fernandes Custodio ${ }^{\star \star \star}$
}

\begin{abstract}
Esse artigo analisa o impacto de política fiscal e de seguridade social em presença de bônus demográfico num modelo de equilíbrio geral dinâmico com agentes se comportando de acordo com a hipótese do ciclo da vida. Permitindo uma estrutura demográfica não estacionária, sob a hipótese do ciclo da vida, o modelo teórico captura o impacto da política fiscal e de seguridade social sobre a distribuição de renda durante a fase de bônus demográfico. 0 método de análise se baseia em técnicas de economia computacional para simular choques demográficos a partir do equilíbrio estacionário do modelo. 0 crescimento provisório da parcela da população correspondente aos trabalhadores causa aumento da poupança e redução da taxa de juros. Já o estoque de capital segue uma trajetória em forma de $U$ invertido, tal como sugerido na literatura. A políticas que elevam o grau de contribuição da seguridade social são ferramentas de estímulo ao consumo e à redistribuição da renda em favor dos aposentados. A principal contribuição do artigo é fornecer uma análise das implicações macroeconômicas do bônus demográfico a partir de um modelo teórico com fundamentos microeconômicos para as decisões de consumo e acumulação de ativos.
\end{abstract}

Palavras-chave: Transição demográfica. Bônus demográfico. Seguridade social. Modelo de ciclo de vida.

\footnotetext{
*Universidade Federal de Santa Catarina (UFSC), Florianópolis-SC, Brasil (henriquerct@gmail.com; https://orcid.org/00000003-4362-3497).

** Universidade do Estado de Santa Catarina (Udesc), Florianópolis-SC, Brasil (patriciabonini@gmail.com; https://orcid. org/0000-0003-0495-4955).

*** Instituto Brasileiro de Ensino, Desenvolvimento e Pesquisa (IDP), Brasília-DF, Brasil (carolinafcustodio@gmail.com; https://orcid.org/0000-0001-9616-8825).
} 


\section{Introdução}

0 interesse dos economistas no processo de transição demográfica se justifica pelo fato de que as mudanças nas características populacionais podem conduzir a alterações diversas no ambiente econômico por ter impactos sobre os movimentos da força de trabaIho, a poupança da economia e, por conseguinte, sobre sua capacidade de crescimento econômico. 0 primeiro dividendo demográfico caracteriza-se pelo estágio da estrutura demográfica, no qual a parcela da população em idade ativa é maior do que aquela fora desse intervalo de idade. Em termos específicos de ampliação da renda per capita, o aumento da oferta de trabalho se dá enquanto o crescimento da população em idade ativa - faixa etária de 15 a 64 anos - é maior do que o crescimento da população total. Por esse critério, o bônus demográfico brasileiro, em curso desde a década de 1970, deve terminar em 2025. 0 impacto das políticas fiscais e de seguridade social no contexto de bônus demográfico ainda é questão que requer estudo, em especial na economia brasileira.

A população brasileira apresentava, até os anos 1960, uma distribuição etária praticamente estável, com perfil extremamente jovem. No final desta década, iniciou-se rápido declínio da taxa de fecundidade, que passou de 6,28 filhos por mulher em 1960, para 2,38 em 2000, com projeção de 1,59 para 2015 (IBGE, 2013). Em consequência, a taxa de crescimento da população brasileira apresenta tendência decrescente e deve alcançar a marca zero entre as décadas de 2040 e 2050 (CARVALHO; GARCIA, 2003; BRITO, 2006).

Projeta-se uma nova distribuição na estrutura etária do Brasil, em que os jovens diminuirão sua parcela na população de $42 \%$ em 1950 para $18 \%$ em 2050, enquanto os idosos aumentarão sua participação de $2,4 \%$ para $19 \%$, no mesmo período. Dessa forma, as projeções do IBGE (2013) apontam que o bônus demográfico brasileiro, que começou na década de 1960, tenha encerramento em 2025.

O objetivo desse artigo é contribuir para o entendimento do impacto de políticas fiscais e de seguridade social sobre o modo como variáveis macroeconômicas chaves renda, consumo e oferta de mão de obra - são afetadas pelo bônus demográfico. Uma importante contribuição do artigo é desenvolver análise embasada num modelo teórico com fundamentos microeconômicos para as decisões individuais. Adota-se um modelo de equilíbrio geral dinâmico (DGE) com hipótese de ciclo de vida, seguindo o esquema proposto por Gertler (1999).

Enquanto Gertler está interessado em realçar as vantagens e apelo realístico da hipótese do ciclo de vida em relação às formulações com horizonte de vida infinito, o presente artigo visa determinar o impacto da transição demográfica sobre a economia. Assim, simulam-se a dinâmica do bônus demográfico e seus efeitos sobre a acumulação de capital, a taxa de juros e a dinâmica do pagamento de seguridade social e arrecadação tributária.

0 artigo está dividido em cinco seções, incluindo esta introdução. A seguir, é feita uma breve revisão de literatura acerca dos dividendos demográficos e seus efeitos teóricos. Posteriormente, definem-se as variáveis e a estrutura do modelo utilizado, bem como 
apresentam-se os efeitos simulados de flutuações no mercado de trabalho. Na sequência, nova simulação é realizada a partir da inserção do papel do governo e da seguridade na economia. Por fim, são discutidos o bônus demográfico no Brasil e as condições da economia brasileira que ajudam e que prejudicam o aproveitamento do bônus.

\section{Perspectiva econômica da transição demográfica}

Uma das mais influentes visões sobre as implicações do crescimento populacional para o crescimento econômico é a de Thomas Malthus (1766-1834), divulgada em 1798. Malthus (1986) viu o aumento da população como obstáculo ao crescimento econômico. Para Alves (2006), a perspectiva de Malthus colocava-se em oposição às visões anteriores de Adam Smith (1723-1790), Marquês de Condorcert (1743-1794) e William Godwin (1756-1836), que divulgavam uma conexão positiva entre crescimento populacional e desenvolvimento econômico. As duas perspectivas opostas sobre as implicações do volume populacional para o crescimento econômico estiveram ainda mediadas pela visão de Marx (1818-1883), de acordo com a qual o crescimento populacional seria neutro em termos de impacto sobre o desenvolvimento econômico.

Os estudos a partir de Thompson (1929) e Notestein (1953) deram início à identificação e investigação da dinâmica das mudanças na estrutura etária e desempenho da economia. A contribuição de Coale e Hoover (1958) já sugeria que a quantidade total de pessoas, a taxa de crescimento e a distribuição etária seriam as principais características determinantes da formação de renda per capita de uma nação.

Como destacam Paiva e Wajnman (2005), as contribuições de Bloomn e Williamson (1997), Mason (2005) e Taylor (1995) foram importantes avanços na compreensão das mudanças na estrutura etária e suas implicações sobre a poupança e o crescimento econômico. Por fim, o foco no quantitativo populacional foi de vez abandonado à medida que as pesquisas sobre demografia ganharam complexidade e chegaram ao resultado de que o crescimento populacional não seria uma variável explicativa do desempenho da renda per capita de uma nação - conforme, por exemplo, Galor e Weil (2009).

\section{Dividendos demográficos e crescimento econômico}

Turra e Queiroz (2005) denominam o primeiro dividendo demográfico, ou bônus demográfico, como o momento em que há um aumento temporário da parcela da população em idade de trabalhar. Para Mason (2005), o primeiro dos dividendos corresponde a um simples crescimento da proporção de trabalhadores, o qual refletirá em uma produção per capita mais elevada, caso se mantenham fixas a produtividade e a taxa de desemprego.

Do ponto de vista da relação entre as gerações que convivem a cada período de tempo, jovens e idosos ficam fora da população economicamente ativa, mas demandam bens e serviços. Assim, a parcela da população em idade ativa precisa manter excedente de renda para prover os grupos jovens e idosos. Este ciclo de vida econômico é ilustrado na Figura 1, 
em que se comparam o rendimento e o consumo per capita por faixa etária. Ainda que cada país possa apresentar formas distintas em seus ciclos, tem-se normalmente um padrão de consumo constante durante todo o período, que é sustentado por um rendimento do trabalho que sobressai apenas no período produtivo da vida.

FIGURA 1

Ciclo de vida econômico

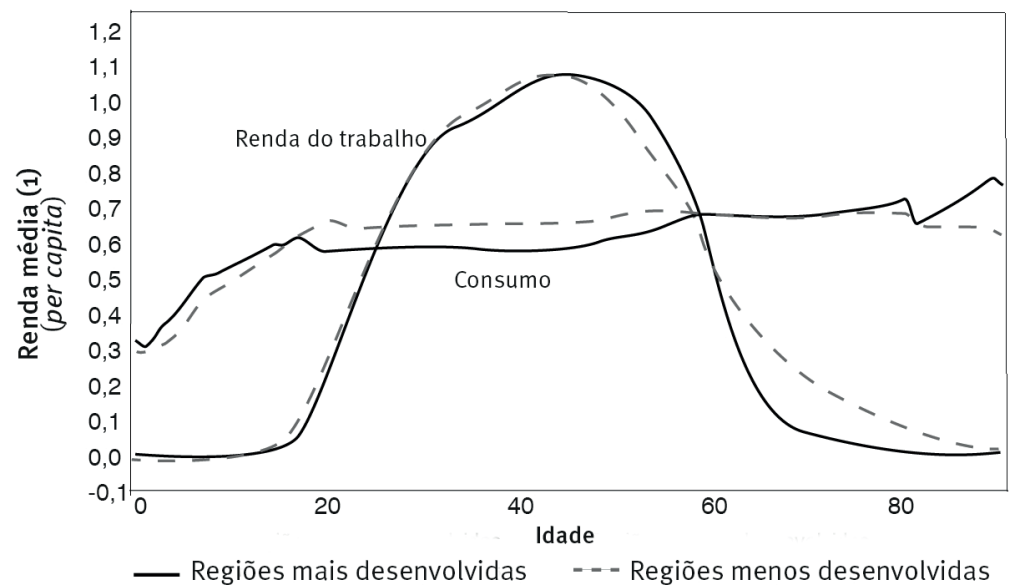

Fonte: UN (2013).

(1) Renda per capita média por idade para faixa etária de 30 a 49 anos.

Como argumentam Croix, Lindh e Malmberg (2009), há duas maneiras tradicionais de se analisar a relação entre tendências demográficas e crescimento econômico. A primeira se baseia na construção de modelos teóricos capazes de fornecer o entendimento dos mecanismos de crescimento, de modo qualitativo ou quantitativo - Bloomn e Williamson (1997), An e Jeon (2006) e Fougere e Merette (2009). Já a segunda maneira analisa as relações empíricas entre variáveis demográficas e do crescimento da renda per capita - Wang e Mason (2005), Turra e Queiroz (2005) e Brito (2006).

Na próxima seção apresenta-se o modelo utilizado neste artigo, seguindo o benchmark proposto por Gertler (1999), que introduz uma hipótese de transição aleatória do grupo em idade ativa para os inativos e sua saída do ciclo. Ferrero (2005) utiliza essa formulação para analisar os efeitos da transição demográfica sobre o saldo do balanço de pagamentos. Já Fujiwara e Teranishi (2008) formulam um modelo novo keynesiano, introduzindo choques estocásticos e concorrência monopolística para analisar o impacto da política monetária em contexto de transição demográfica.

\section{Um modelo de crescimento econômico sob a hipótese do ciclo de vida}

Ao seguir Gertler (1999), são simulados os impactos do bônus demográfico sobre: a acumulação de capital; a distribuição de riqueza; e o financiamento da seguridade social. 
Uma das vantagens desta formulação é que, mesmo lidando com uma estrutura de gerações sobrepostas, o modelo é parcimonioso. Outra característica do modelo é a não observância do princípio da equivalência ricardiana devido à hipótese comportamental do ciclo de vida e ao horizonte finito de otimização dos agentes.

\section{Hipóteses do modelo}

Define-se uma economia fechada e sem governo, com indivíduos que suavizam o consumo intertemporalmente, de acordo com a HCV de Modigliani-Brunberger. Em cada ponto no tempo convivem duas coortes de idade, a dos trabalhadores $(w)$ e a dos aposentados $(r)$.

\section{Demografia}

Em cada período $(t)$, um trabalhador possui a probabilidade $\omega$ de permanecer como tal no período seguinte e a probabilidade 1- $\omega$ de entrar na fase de aposentadoria. Desse modo, o tempo médio de serviço dos indivíduos é de $\frac{1}{1-\omega}$. Um aposentado possui uma probabilidade $\gamma$ de continuar vivo no período $t+1$ e o tempo médio de aposentadoria é de $\frac{1}{1-\gamma}$. Como um recurso metodológico que garante a tratabilidade do modelo de gerações sobrepostas, assume-se que $\omega$ e $\gamma$ são constantes e independentes da idade.

A população cresce à taxa $n$, de modo que, em cada período, são acrescidos (1- $\omega+n)$ novos trabalhadores. Supõe-se ainda que os trabalhadores ofertam inelasticamente sua unidade de trabalho, enquanto os aposentados não ofertam qualquer tipo de serviço. ${ }^{1}$

A dinâmica do número de trabalhadores, $N^{w}$, pode ser definida da seguinte forma:

$N_{t+1}^{w}=(1-\omega+n) N_{t}^{w}+\omega N_{t}^{w}=(1+n) N_{t}^{w}$

Já a dinâmica do número de aposentados, $N^{r}$, pode ser definida como:

$N_{t+1}^{r}=(1-\omega) N_{t}^{w}+\gamma N_{t}^{r}$

A relação entre o número de aposentados e o número de trabalhadores se define como, $\psi_{t}=\frac{N_{t}^{r}}{N_{t}^{W}}$, uma simplificação do modelo para representar a taxa de dependência de idosos. ${ }^{2}$ Por hipótese, a taxa de crescimento da população é constante. Assim, a taxa de dependência de idosos também se mantém constante e pode ser expressa como:

$\psi_{t}=\frac{1-\omega}{(1+n-\gamma)}$

Portanto, a proporção dos aposentados em relação aos trabalhadores depende positivamente da probabilidade de sobrevivência, $\gamma$, e negativamente da probabilidade de aposentadoria e da taxa de crescimento da população.

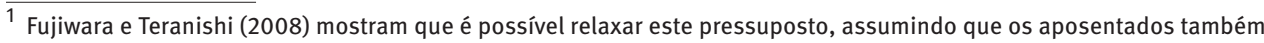
podem ofertar trabalho.

2 Segundo o relatório das Nações Unidas (UN, 2013), a taxa de dependência reflete a relação entre a proporção de dependentes e o grupo de pessoas em idade economicamente ativa. Em termos práticos, trata-se da razão entre os dependentes - soma do número de crianças (com menos de 15 anos de idade) com o número de pessoas idosas (com idade igual ou maior que 65 anos) - e a população em idade ativa (de 15 a 64 anos).
} 


\section{Preferências por consumo}

Assume-se que as preferências por consumo são do tipo Constant Elasticity of Substitution (CES), denotando por $V$ o valor da utilidade individual, $C$ o consumo, $\beta$ o fator de desconto intertemporal subjetivo e $\mathrm{z}=\{w, r\}$ indica que o consumidor é ou trabalhador ou aposentado. A probabilidade de sobrevivência, $\gamma$, distingue o fator de desconto subjetivo dos indivíduos em cada uma dessas duas coortes de idade:

$\beta_{t, t+1,}^{z}= \begin{cases}\beta \gamma_{t, t+1,}, & \text { se } z=r \\ \beta, & \text { se } z=w\end{cases}$

As preferências por consumo dessa população são representadas pela seguinte função utilidade aditiva e separável no tempo:

$\left.V_{t}^{z}=\left[\left(C_{t}^{z}\right)^{\rho}+\beta^{z} E_{t} V_{t+1} \mid z\right\}^{\rho}\right]^{1 / \rho}$

O parâmetro $\rho$ é a taxa de substituição intertemporal e implica que os indivíduos maximizam a utilidade de modo a suavizar o consumo ao longo do tempo. 0 desejo de suavizar o consumo significa que a elasticidade de substituição intertemporal é finita e corresponde a $\sigma=\frac{1}{1-\rho}$.

0 termo $E_{t}\left\{V_{t+1} \mid z\right\}$ representa a expectativa dos indivíduos, no período corrente $t$ sobre o valor de utilidade futura, condicional a ser do tipo $z$ (trabalhador ou aposentado) e estar vivo no período $t+1$. Assumindo que os indivíduos são neutros ao risco - ou seja, se preocupam apenas com o primeiro momento da renda esperada -, essa expectativa pode ser expressa como, respectivamente, para os trabalhadores e aposentados:

$E_{t}\left\{V_{t+1} \mid w\right\}=\omega\left(V_{t+1}^{w}\right)+(1-\omega)\left(V_{t+1}^{r}\right)$

e

$E_{t}\left\{V_{t+1} \mid r\right\}=\left(V_{t+1}^{r}\right)$

A decisão de consumo presente dependente somente da expectativa de consumo futuro, dada a taxa de desconto intertemporal. Como as preferências são estabelecidas em termos do valor médio da função $V$ no período seguinte, os indivíduos levam em conta apenas a média da renda esperada quando otimizam o consumo. Por isso, as regras de decisões são dadas em equivalente-certeza diante dos riscos idiossincráticos da renda, fugindo ao padrão das funções utilidade do tipo Von Neumann-Morgernstern.

Restrição orçamentária e a decisão de consumo

Consideramos que, para um aposentado, o estoque de ativos físicos no começo de um período $t$ seja representado por $A_{t}^{r}$, sendo o retorno bruto sobre esses ativos entre $t$ e $t-1$, $R_{t}$, e $C_{t}^{r}$ represente o consumo no período $t$. 0 aposentado não oferta trabalho, de modo que sua restrição orçamentária intertemporal deve corresponder a:

$A_{t+1}^{r}(i)=\frac{R_{t} A_{t}^{r}(i)}{\gamma}-C_{t}^{r}(i)$ 
Assume-se ainda que não haja risco agregado, de modo que, para um aposentado que sobrevive até o período seguinte, $t+1$, o consumo no período $t+1$ é certo. Além disso, para eliminar os riscos sobre a renda dos aposentados, assume-se que cada um deles participa de um mercado perfeito de anuidades. Essa hipótese homogeneíza os aposentados, de modo que a solução para sua propensão marginal a consumir deve ser similar à solução padrão para preferências do tipo CES, ou seja, será a mesma para todos os indivíduos na coorte de idade.

Já um trabalhador representativo, $j$, oferta trabalho inelasticamente, recebendo renda do trabalho, $W$, e possuindo ainda renda dos ativos. Sua restrição orçamentária intertemporal pode ser escrita como:

$A_{t+1}^{w}(j)=R_{t} A_{t}^{w}(j)+W_{t}-C_{t}^{w}(j)$

A riqueza humana dos trabalhadores, $H_{t}$, corresponde ao valor presente descontado do fluxo de renda do trabalho:

$H_{t}(j)=\Sigma_{v=0}^{\infty} \frac{w_{t+v}}{\Pi_{z=1}^{v} R_{t+z} \frac{\Omega_{t+1}}{\omega}}$

0 fator de ponderação do retorno bruto, $\Omega$, surge do problema de escolha intertemporal entre consumo e poupança e sua dedução, mostrada no Anexo. Esse fator depende positivamente da probabilidade de aposentadoria, $\omega$, e da relação entre as propensões marginais a consumir, $P_{m g} C$, dos aposentados e dos trabalhadores, $\epsilon$. Sua dinâmica pode ser descrita como:

$\Omega_{t+1}=\omega-(1-\omega) \in_{t+1}^{\frac{1}{1-\sigma}}$

À medida que $\Omega_{t+1}>1$, a propensão marginal a consumir dos aposentados é maior do que a dos trabalhadores, ou seja, $\epsilon_{t+1}>1$. Com isso, a taxa de desconto da renda futura do trabalho é maior do que a do retorno sobre os ativos $R_{t}$. Com o horizonte finito de otimização, os indivíduos consumirão todo o seu capital acumulado, sem deixar heranças. Assim, dada a preferência pela suavização do consumo durante a vida, qualquer aumento da riqueza, mesmo que seja esperado para o futuro, implica que o consumo cresça já no período presente.

Maximização individual de utilidade ${ }^{3}$

Os aposentados decidem sobre o consumo em cada período de modo a maximizar (5), dados (7) e (8), com $\beta^{z}=\beta \gamma$ e a condição terminal que eles paguem todas as suas dívidas antes de morrer. Assim, para os aposentados a equação de Euler implica que sua decisão de consumo obedecerá à seguinte regra:

$C_{t+1}^{r}(i)=\epsilon_{t} \pi_{t}\left(\frac{R_{t}(i)}{\gamma}\right) A_{t}^{r}(i)$

Em que $\epsilon_{t} \pi_{t}$ é a propensão marginal a consumir, $P_{m g} C$, a riqueza dos aposentados:

\footnotetext{
${ }^{3}$ A solução para o problema de maximização individual que gera as equações diferenciais para o consumo dos aposentados e consumo dos trabalhadores, bem como a evolução da variável de distribuição de renda, está em Gertler (1999, Apêndice).
} 
$\epsilon_{t} \pi_{t}=1-\left(R_{t+1}^{\sigma-1} \beta^{\sigma} \gamma\right) \frac{\epsilon_{t} \pi_{t}}{\epsilon_{t+1} \pi_{t+1}}$

Assim, quando $\sigma=1$, a $P_{m g} C$ dos aposentados varia somente em função da taxa de desconto intertemporal, $\beta \gamma$. Este é o caso em que $\rho=0$ e função utilidade (5) assume a forma que descreve a neutralidade ao risco, correspondendo a preferências logarítmicas.

Já os trabalhadores maximizam a utilidade (5) quando $\beta^{z}=\beta$, dados (6) e (9) e a restrição (8) torna-se efetiva quando passam para a fase de aposentadoria. A equação de Euler impõe que sua decisão de consumo seja descrita da seguinte maneira:

$C_{t+1}^{w}(j)=\pi_{t}\left(R_{t} A_{t}^{w}(j)+H_{t}(j)\right)$

Em que $H$ é a riqueza humana e $\pi_{t}$, a $P_{m g} C$ dos trabalhadores:

$\pi_{t}=1-\left(R_{t+1} \Omega_{t+1}\right)^{\sigma-1} \beta^{\sigma} \frac{\pi_{t}}{\pi_{t+1}}$

O lado da produção

Cada empresa produz o produto, $Y$, a partir do uso de capital, $K$, e mão de obra, $N$, combinados numa função de produção do tipo Cobb-Douglas. Uma variável $X$ associada à tecnologia permite que o fator trabalho seja inserido em termos de trabalho efetivo, $X_{t} N_{t}$, sendo $X_{t}$ uma variável exógena de aumento da efetividade do trabalho:

$Y_{t}=\left(X_{t} N_{t}\right)^{\alpha} K_{t}^{1-\alpha}$

Em que $\alpha \in(0,1)$. Por hipótese, este aumento da produtividade cresce a uma taxa constante e igual a $x$. As famílias são detentoras do capital e há um custo de depreciação correspondente a $\delta$.

0 ambiente de mercado é de concorrência nos mercados de produto e de fatores de produção, com perfeita flexibilidade de preços. Assim, $W$ e $R$ representarão, respectivamente, o salário real e a taxa de juros reais, correspondentes a custo do trabalho e do capital, respectivamente. Perfeita simetria entre as firmas implicará, no equilíbrio competitivo, que as vaiáveis agregadas corresponderão ao valor do nível da variável para uma empresa representativa.

Governo

0 consumo do governo, num dado período, é igual a $G_{t}$. Além disso, o governo transfere uma quantidade $E_{t}$ de recursos aos aposentados, na forma de seguridade social. Para equalizar os gastos, o governo gera uma arrecadação fiscal, $T_{t}$, imposta sobre a renda dos trabalhadores, e emite títulos públicos com pagamento futuro, $B_{t+1}$.

A emissão de títulos do governo é uma ferramenta para equacionamento de débitos que está sujeita à seguinte condição de solvência intertemporal:

$R_{t} B_{t}=\Sigma_{v=0}^{\infty} \frac{T_{t+v}}{\prod_{z=1}^{v} R_{t+z}}-\Sigma_{v=0}^{\infty} \frac{G_{t+v}}{\prod_{z=1}^{v} R_{t+z}}-\sum_{v=0}^{\infty} \frac{R_{t+v}}{\prod_{z=1}^{v} R_{t+z}}$

Sucessivas iterações de (17) resultam em uma condição de solvência que deve ser satisfeita em cada período: 
$B_{t+1}=R_{t} B_{t}+G_{t}+E_{t}-T_{t}$

No que se segue, o modelo até aqui apresentado é resolvido para caracterizar o equilíbrio em dois contextos, numa economia sem governo e numa economia com governo. $\mathrm{Na}$ perspectiva da análise de Gertler (1999), o objetivo da introdução do governo é avaliar o impacto da política fiscal e da seguridade social.

\section{Dinâmica do equilíbrio geral da economia sem governo}

Em equilíbrio, os consumidores maximizam suas utilidades sujeitas às suas respectivas restrições orçamentárias e as empresas maximizam o lucro, dada a tecnologia. A simetria dentro de cada um dos grupos - aposentados e trabalhadores - facilita a agregação. Em especial, as propensões marginais a consumir devem ser iguais em cada uma das coortes de idade.

A equação (12) representa o consumo agregado dos aposentados, graças à homogeneidade de $\epsilon_{t} \pi_{t}$. 0 retorno bruto agregado será igual a $R_{t}$, pois, ainda que cada aposentado receba um retorno igual a $\frac{R_{t}}{\gamma}$ em $t-1$, somente uma fração igual a $\gamma$ sobrevive para o período $t$. Assim, o consumo agregado total dos aposentados é dado por:

$C_{t}^{r}=\epsilon_{t} \pi_{t} R_{t} A_{t}^{r}$

Similarmente, o consumo agregado dos trabalhadores pode ser obtido a partir da média dos níveis de consumo individuais graças à hipótese de neutralidade ao risco e consequente homogeneidade da propensão marginal a consumir. Assim, a agregação em $j$, da equação (14), resulta que:

$C_{t}^{w}=\pi_{t}\left(R_{t} A_{t}^{w}+H_{t}\right)$

Sendo que a riqueza humana agregada corresponde a:

$H_{t}=\sum_{v=0}^{\infty} \frac{N_{t+v} W_{t+v}}{\prod_{z=1}^{v} R_{t+1} \frac{\Omega_{t+1}}{\omega}}=N_{t} W_{t}+\frac{H_{t+1}}{(1+n) R_{t+1} \frac{\Omega_{t+1}}{\omega}}$

0 termo $(1+n)$ na equação (21) implica que a fração dos salários totais alocada aos trabalhadores diminui a cada novo período em que cresce o total de mão de obra disponível. Destaca-se que este é o terceiro elemento que distingue modelos de ciclo de vida, quais sejam:

- a expectativa de aposentadoria dada pelo parâmetro $\omega$;

- o aumento da utilidade com a suavização do consumo refletida pela presença de $\Omega_{t+1}$ o termo $R_{t+z} \Omega_{t+z} / \omega$ diferencia esse modelo do contexto de horizonte infinito por depender da probabilidade de aposentadoria $\omega$. Uma vez que $\Omega_{t+1}>1$ e $\omega<1$, a taxa de desconto é mais elevada, implicando menor consumo e maiores taxas de poupança para financiar o consumo durante a aposentadoria;

- o crescimento da força de trabalho. 
A determinação de $A_{t}$, como a soma dos ativos agregados, e de $\lambda_{t}$, como a fração dos ativos em posse dos aposentados, permite chegar à função de consumo agregado a partir da combinação das equações (19) e (20):

$C_{t}=\pi_{t}\left\{\left[1+\left(\epsilon_{t}-1\right) \lambda_{t}\right] R_{t} A_{t}+H_{t}\right\}$

Quando a propensão marginal a consumir dos aposentados for maior do que a dos trabalhadores, o parâmetro $\epsilon_{t}>1$, o que é uma hipótese razoável uma vez que não se presume a utilidade em deixar heranças e, portanto, a formação de poupança por parte dos aposentados é desnecessária. Então, de acordo com a expressão (22), um aumento de $\lambda_{t}$ elevará a demanda agregada. Esta relação tem implicações importantes para a maneira como as políticas de seguridade social e previdência impactam a economia. Uma característica desta economia do ciclo de vida é que no estado estacionário haverá apenas duas variáveis endógenas: $\lambda_{t}$ e $K$.

É possível explorar a lei de movimento da distribuição de riquezas entre as coortes de idade, $\lambda$, a partir da agregação das equações (8) e (9), de modo que:

$\lambda_{t+1} A_{t+1}=\lambda_{t} R_{t} A_{t}-C_{t}^{r}+(1-w)\left[\left(1-\lambda_{t} R_{t} A_{t}+W_{t}-C_{t}^{w}\right]\right.$

0 total de ativos mantidos pelo grupo de aposentados entre o período $t$ e $t+1$, lado esquerdo da equação (23), depende de sua poupança no período $t$ - os primeiros dois termos no lado direito da equação - e dos ativos acumulados pelos trabalhadores, no período $t$, que migram dessa coorte para a coorte de aposentados no início de $t+1-$ os termos restantes no lado direito da expressão.

Uma vez que o total de ativos que continuam nas mãos dos trabalhadores no período $t+1$ deve corresponder a $\left(1-\lambda_{t+1}\right) A_{t+1}$, este deve corresponder ao montante de ativos mantidos ao longo de $t$ vezes a proporção daqueles que continuam como trabalhadores, $w$, a expressão acima pode ser escrita como:

$\lambda_{t+1}=\omega\left(1-\epsilon_{t} \pi_{t}\right) \lambda_{t} R_{t} \frac{A_{t}}{A_{t+1}}+(1-\omega)$

Por fim, para fechar o modelo, resta descrever a decisão de produção, que gera o salário real e a taxa de retorno sobre o capital, que equilibra cada um dos seus respectivos mercados. No equilíbrio, esses preços devem se igualar às suas respectivas demandas.

Pelo lado das firmas, a hipótese de maximização de lucro em ambiente competitivo implica que, no equilíbrio simétrico, as empresas irão contratar força de trabalho até o ponto em que o salário real iguale o produto marginal do trabalho.

$W_{t}=\alpha \frac{Y_{t}}{N_{t}}$

A rentabilidade do capital será igual a seu produto marginal menos a taxa de depreciação. $R_{t}=(1-\alpha) \frac{Y_{t}}{K_{t}}+(1-\delta)$ 
A formação de poupança corresponde à acumulação da riqueza financeira que financia acumulação de capital físico. Assim, a soma de ativos nesta economia deve igualar o estoque de capital físico a cada ponto no tempo:

$A_{t}=K_{t}$

Por fim, com a economia fechada e sem governo, o estoque de capital evolui de acordo com a seguinte equação:

$K_{t+1}=Y_{t}-C_{t}+(1-\delta) K_{t}$

\section{Caracterização do estado estacionário na economia sem governo}

A caracterização do equilíbrio competitivo em estado estacionário é mostrada integralmente por Getler (1999). Resumidamente, o equilíbrio é definido por um sistema de equações com duas variáveis endógenas predeterminadas, quais sejam: o estoque de capital físico e a parcela da riqueza não humana que fica com os aposentados, $\left\{K_{t+1}, \lambda_{t+1}\right\}$. As demais variáveis endógenas $\left\{\pi_{t}, \in_{t}, H_{t}^{w}, C_{t}, W_{t}, R_{t}, A_{t}\right\}$ são definidas pelas equações (13), (15), (16), (22), (25), (26), (27) e (28) e pelas variáveis determinadas por fatores exógenos $N_{t}$ e $X_{t}$.

No estado estacionário, o tamanho da força de trabalho e o avanço tecnológico, $N_{t}$ e $X_{t}$, aumentam à taxa de crescimento exógeno $(1+\chi)(1+n)$, determinando o crescimento do trabalho efetivo, $X_{t} N_{t}$. Em razão dessa elevação, as variáveis serão normalizadas em relação ao produto. Denotaremos a variável por unidades de produto por sua respectiva letra em caractere em minúsculo. Assim, as variáveis passam a ser definidas em termos de seu nível em relação ao produto e simplificadas as equações existentes, de maneira que o sistema de equações possa ser descrito em apenas nove variáveis endógenas $\left\{k_{t}, \lambda_{t}, \pi_{t}, \Omega_{t}, h_{t}, c_{t}, R_{t}, \alpha_{t}\right\}$, e nove equações (A.1 a A.9, no Anexo A).

A solução numérica do modelo, no presente trabalho, mostrada na Tabela 2, foi obtida com base em calibragem usando os valores ${ }^{4}$ benchmark mostrados na Tabela 1.

TABELA 1

Definição dos parâmetros

\begin{tabular}{cll}
\hline Parâmetro & Valor & \multicolumn{1}{c}{ Descrição } \\
\hline$\beta$ & 0,989 & Fator de desconto subjetivo \\
$\delta$ & $6 \%$ & Taxa de depreciação do capital \\
$\sigma$ & 0,25 & Elasticidade de substituição intertemporal \\
$\alpha$ & 0,667 & Participação da força de trabalho na produção \\
$(1-\omega)^{-1}$ & 40 & Tempo médio de trabalho \\
$(1-\gamma)^{-1}$ & 10 & Tempo médio de aposentadoria \\
$n$ & 0,01 & Taxa de crescimento da população \\
\hline$x$ & 0,01 & Taxa de mudança na produtividade
\end{tabular}

Fonte: Elaboração dos autores.

0 parâmetro foi calibrado para que o tempo médio de vida ativa fosse de 40 anos, enquanto Gertler utiliza um valor associado a 45 anos. Dados os valores dos parâmetros

\footnotetext{
4 Esta definição dos parâmetros segue os trabalhos de Moura (2015), referente a $\beta$, Gertler (1999), referente a $\sigma$ e $\alpha$, e de Ferrero et al. (2005), para o valor de $\delta$.
} 
da Tabela 1 e o sistema de equações (A.1) a (A.9), no Anexo A, é possível encontrar uma única solução numérica para o estado estacionário (Tabela 2). Destaca-se que a relação entre as propensões marginais a consumir dos aposentados e trabalhadores indica que estes últimos estão menos propensos ao consumo $(\epsilon=2,4)$, o que faz sentido, uma vez que para os aposentados não há mais necessidade de manter capital acumulado.

TABELA 2

Valores no estado estacionário da economia sem governo

\begin{tabular}{cccccccccc}
\hline $\boldsymbol{k}$ & $\boldsymbol{\lambda}$ & $\boldsymbol{\pi}$ & $\boldsymbol{\epsilon}$ & $\boldsymbol{\Omega}$ & $\boldsymbol{h}$ & $\boldsymbol{c}$ & $\boldsymbol{R}$ & $\boldsymbol{a}$ & $\boldsymbol{\psi}$ \\
\hline 5,455 & 0,200 & 0,0429 & 2,400 & 1,055 & 8,652 & 0,672 & 1,001 & 5,455 & 0,25 \\
\hline
\end{tabular}

Fonte: Elaboração dos autores.

A relação $\frac{A_{t}}{Y_{t}}=a$ segue o mesmo impacto que $k$ porque no equilíbrio dinâmico $A=K-$ equação (27). A participação do consumo na renda, c, é de 67,2\%. Destaca-se também que a razão de dependência igualou-se a $25 \%(\psi=0,25)$ e, assim, os aposentados representam um quarto da população e detêm um quinto dos ativos $-\lambda=0,20$.

Qualquer choque que tenha um impacto negativo sobre $\lambda$ causará redução do consumo agregado, aumentando a poupança e o capital físico, $K$.

\section{Dinâmica de equilíbrio com governo}

A introdução do governo não afeta a propensão marginal a consumir dos aposentados nem a dos trabalhadores. Contudo, a ação do governo afeta a renda disponível e a riqueza de cada um desses grupos.

$\mathrm{Na}$ economia com governo há um incremento na renda dos aposentados correspondente às transferências da seguridade social. Assim, a função consumo agregada dos aposentados passa a ser representada por:

$C_{t}^{r}=\epsilon_{t} \pi_{t}\left[R_{t} A_{t}^{r}+S_{t}\right]$

Sendo $\epsilon_{t} \pi_{t}$ definido pela equação (13) e $S_{t}$ o valor total capitalizado dos benefícios de previdência social num dado período $t$ :

$S_{t}=\sum_{v=0}^{\infty} \frac{E_{t+v}}{\prod_{z=a}^{v}(1+n) \frac{R_{t+1}}{\gamma}}$

O que pode ser simplificado:

$S_{t}=E_{t}+\frac{S_{t+1}}{(1+n) \frac{R_{t+1}}{\gamma}}$

Assim, a soma das transferências depende da taxa de crescimento do total de aposentados, $(1+n)$, e da probabilidade de sobrevivência, $y$.

Os trabalhadores, por sua vez, agora têm a expectativa de receber os benefícios da aposentadoria no futuro, $S_{t}^{w}$. Assim, sua função consumo agregada inclui o termo associado à seguridade:

$C_{t}^{w}=\pi\left[A_{t}^{w}+H_{t}+S_{t}^{w}\right]$ 
Além disso, a cobrança de impostos sobre a renda do trabalho implica que a riqueza humana diminui e passa a ser computada a partir do seguinte fluxo de desconto dos impostos, $T_{t}$.

$H_{t}=\sum_{v=0}^{\infty} \frac{N_{t+v} W_{t+v}-T_{t+v}}{\prod_{z=1}^{v} R_{t+z}+\Omega_{t+z} / \omega}=N_{t} W_{t}-T_{t}+\frac{H_{t+1}}{(1+n) R_{t+1} \Omega_{t+z} / \omega}$

Já o montante de benefícios esperados pelos trabalhadores no futuro vai depender da taxa de crescimento do número de aposentados, da probabilidade de se manter trabaIhador no período subsequente e do valor da seguridade por contribuinte, o que pode ser designado por $\hat{S}_{t}=\frac{S_{t}}{\psi N_{t}}$, sendo que $\psi N_{t}$ representa o número de aposentados no período $t$. Assim, $S_{t}^{W}$ pode ser representada por:

$S_{t}^{w}=\sum_{v=0}^{\infty} \frac{(1-\omega) w^{v} N_{t}\left(\frac{\epsilon_{t+1+v} \widehat{S_{t+1+v}}}{R_{t+v} \Omega_{t+v}}\right)}{\Pi_{z=1}^{v} R_{t+z} \Omega_{t+v}}$
$S_{t}^{w}=(1-w) N_{t}\left(\frac{\epsilon_{t+1} \widehat{S_{t+1}}}{R_{t+1} \Omega_{t+1}}\right)+\frac{S_{t+1}^{w}}{(1+n) R_{t+1} \Omega_{t+1} / \omega}$

Agregando as equações (29) e (32), chega-se a uma única função consumo agregada, a qual é representada por:

$C_{t}=\pi_{t}\left[(1-\lambda) R_{t} A_{t}+H_{t}+S_{t}^{w}+\epsilon_{t}\left(\lambda_{t} R_{t} A_{t}+S_{t}\right)\right]$

A equações (33) a (35) mostram que as variáveis associadas ao governo podem impactar o consumo diretamente, por meio da seguridade, e indiretamente, a partir dos impostos que afetam a riqueza humana. A transferência governamental de benefícios para os aposentados é um instrumento de política que incentiva o consumo, tanto dos aposentados quanto dos trabalhadores - devido à hipótese do ciclo de vida e consequente suavização do consumo. Esse efeito é intensificado porque os aposentados têm propensão marginal a consumir mais alta do que os trabalhadores.

Por fim, um aspecto importante da presença do governo é a inobservância da equivalência ricardiana. Enquanto o governo pode financiar sua dívida corrente à taxa de desconto $R_{t}$, os consumidores descontam os impostos futuros a uma taxa superior e igual a $\frac{(1+n) R_{t} \Omega_{t}}{\omega}$. Assim, políticas que posterguem os impostos acabam por aumentar $H_{t} \mathrm{e}$ estimular o consumo.

Tanto os benefícios sociais quanto os impostos influenciam a distribuição de renda entre as coortes da população. A dinâmica distributiva entre aposentados e trabalhadores passa a depender do montante de pagamento de seguridade, $E$ :

$\lambda_{t+1} A_{t+1}=\lambda_{t} R_{t} A_{t}+E_{t}-C_{t}^{r}+(1-\omega)\left[\left(1-\lambda_{t}\right) R_{t} A_{t}+N_{t} W_{t}-T_{t}-C_{t}^{w}\right]$

$\lambda_{t+1}=\omega\left(1-\epsilon_{t} \pi_{t}\right) \lambda_{t} \frac{R_{t} A_{t}}{A_{t+1}}+\frac{w\left[E_{t}-\epsilon_{t} \pi_{t} S_{t}\right]}{A_{t+1}}+(1-\omega)$

Além disso, o equilíbrio entre os ativos financeiros e o capital físico agora inclui o financiamento da dívida pública:

$A_{t}=K_{t}+B_{t}$ 
Correspondentemente, do lado dos gastos, o consumo do governo se soma ao dos aposentados e trabalhadores, reduzindo a poupança total da economia. Assim, a acumulação de capital físico diminui:

$K_{t+1}=Y_{t}-C_{t}-G_{t}+(1-\delta) K_{t}$

Considerando que o governo fixa suas taxas de gasto público, pagamentos da seguridade e o estoque de títulos, estes podem ser denominados por $\bar{g}_{t}, \bar{e}_{t}$ e $\bar{b}_{t}$, respectivamente. Assim, define-se:

$G_{t}=\bar{g}_{t} Y_{t}$

$E_{t}=\bar{e}_{t} Y_{t}$

$B_{t}=\bar{b}_{t} Y_{t}$

Dados esses instrumentos de política fiscal, o governo terá de ajustar o nível de impostos, $T_{t}$, de modo a equilibrar seu orçamento, de acordo com a restrição (18). É esperado que tanto os gastos quanto a emissão de títulos do governo tenham efeitos negativos sobre o estoque de capital, estimulando o consumo. Por sua vez, um aumento no grau de transferências deve elevar o valor das variáveis $S_{t}$ e $S_{t}^{w}$. Como os aposentados possuem $P_{m g} C$ maior que os trabalhadores, o consumo total aumenta e o capital diminui.

\section{Caracterização do estado estacionário da economia com governo}

O sistema de equações pode ser especificado a partir da definição das variáveis endógenas predeterminadas $\left\{K_{t+1}, \lambda_{t+1}\right\}$, representadas nas equações (35) e (37), com as variáveis endógenas já definidas no primeiro sistema $\left\{\pi_{t}, \epsilon_{t}, \Omega_{t}, H_{t}, C_{t}, W_{t}, R_{t}\right\}$, nas equações (13), (11), (10), (32), (34), (35) e (36) e pelas variáveis endógenas, incluídas no modelo para captar o efeito de políticas do governo sobre o ciclo de vida $\left\{T_{t}, S_{t}\right.$ e $\left.S_{t}^{w}\right\}$, representadas nas equações (18), (30) e (32), bem como os fatores exógenos $N_{t}$ e $X_{t}$. Novamente, as variáveis são normalizadas em relação a $Y_{t}$, resultando em um modelo de doze equações, apresentado no Anexo B.

Como em Gertler (1999), são mantidos os valores dos parâmetros, de acordo com a Tabela 1, com exceção do fator de desconto subjetivo, $\beta$, que foi alterado para 1. Além disso, definem-se os valores de $\bar{g}_{t}, \bar{b}_{t}$ e $\bar{e}_{t}$ iguais a $0,2,0,25$ e $0,075,{ }^{5}$ respectivamente. Assim, obtém-se a solução numérica para os valores das variáveis no estado estacionário da economia modelo com governo, mostrados na Tabela 3.

TABELA 3

Valores no estado estacionário da economia com governo e benefícios sociais

\begin{tabular}{cccccccccccc}
\hline $\boldsymbol{k}$ & $\boldsymbol{\lambda}$ & $\boldsymbol{\pi}$ & $\boldsymbol{\epsilon}$ & $\boldsymbol{\Omega}$ & $\boldsymbol{h}$ & $\boldsymbol{c}$ & $\boldsymbol{R}$ & $\boldsymbol{a}$ & $\boldsymbol{S}$ & $\boldsymbol{S}^{\boldsymbol{w}}$ & $\boldsymbol{t}$ \\
\hline 2,88 & 0,24 & 0,06 & 2,01 & 1,03 & 3,36 & 0,62 & 1,05 & 3,08 & 0,82 & 0,50 & 0,28 \\
\hline
\end{tabular}

Fonte: Resultado da solução numérica do modelo - calculado no GNU Octave.

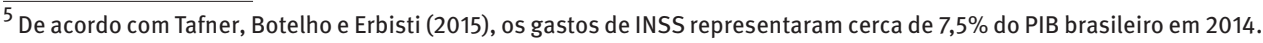


A primeira diferença que aparece quando se comparam as Tabela 3 e 2 é que agora a razão entre ativos e produto, $a$, é maior do que razão capital/produto, $k$. Uma parte da poupança dos agentes privados é direcionada ao financiamento da dívida pública. Com isso, a taxa de juros $R$ é maior agora - passando de $0,1 \%$ para $5 \%$, mesmo tendo sido elevado o desconto intertemporal para $\beta=1$.

Pode-se notar que a transferência do governo aos aposentados resulta em uma maior proporção dos ativos nas mãos dos aposentados, passando de $20 \%$ para $24 \%$ - agora $\lambda=0,24$. As propensões marginais a consumir dos aposentados e dos trabalhadores aumentam devido à expectativa de retornos futuros dos benefícios da seguridade. Porém, o aumento da propensão marginal a consumir dos aposentados, $\pi \epsilon$, é de $25,6 \%$, enquanto o acréscimo da propensão marginal a consumir a riqueza por parte dos trabalhadores, $\pi$, é de $40 \%$.

A proporção do produto destinado ao consumo, $c$, também diminui. Porém, vale notar que sua redução é expressivamente menor do que o decréscimo do capital, ilustrando o efeito deslocamento da política fiscal.

\section{Impactos da demografia e da política fiscal}

Nesta seção são avaliados os efeitos macroeconômicos de choques na taxa de crescimento populacional sobre o estado estacionário das economias com governo e sem governo. Neste artigo, são usados métodos de economia computacional empregando a linguagem GNU Octave.

A partir dos níveis iniciais das variáveis-chave da solução de equilíbrio de longo prazo mostrados nas Tabelas 2 e 3, um choque no parâmetro de crescimento populacional, $n$, causa um impacto sobre as variáveis, que se dissipa ao longo o tempo. 0 modo como respondem aos choques é governado pelas equações (A.1) a (A.8) e (B.1) a (B.12), nos Anexos A e B.

Para avaliar os efeitos do bônus demográfico sobre os valores de equilíbrio de longo prazo das variáveis, simula-se um choque positivo na taxa de crescimento do número de trabalhadores, $n$, a qual seguirá um processo autorregressivo de ordem 1. A defasagem entre a trajetória da PIA e a da população total, característica do bônus demográfico, constitui um aumento da população potencialmente disponível para o trabalho. Desse modo, um aumento da taxa de crescimento dos trabalhadores, no presente modelo, simula fielmente o primeiro dividendo demográfico.

Na Figura 2, o gráfico à esquerda ilustra a reação da taxa de crescimento da população, $n$, submetida a um choque positivo e, à direita, seu impacto sobre a proporção de aposentados e trabalhadores, $\psi$. 0 modo como a taxa de crescimento $n$ afeta a razão de dependência é governado pela expressão (3) e independe da presença do governo na economia modelo.

0 choque em $n$ causa uma redução inicial na razão de dependência, que vai se dissipando à medida que o choque desacelera e a probabilidade de aposentadoria, $\gamma$, volta $a$ governar o fluxo de trabalhadores e aposentados, de acordo com a expressão (3). 
FIGURA 2

Choque na taxa de crescimento da população e na razão de dependência

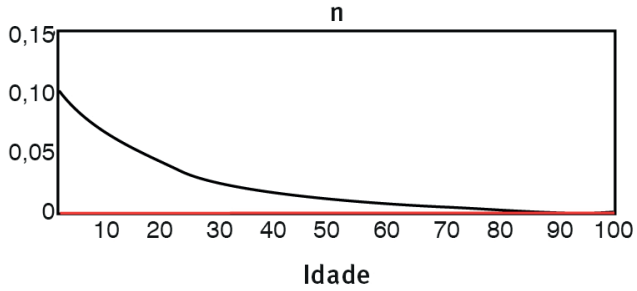

psi

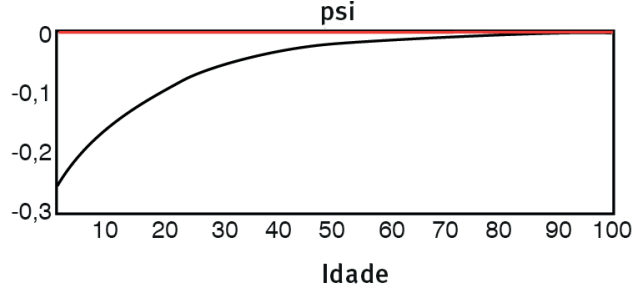

Fonte: Elaboração dos autores.

A Figura 3 mostra os efeitos desse choque sobre as outras nove variáveis, cujos valores de estado estacionário são mostrados na Tabela 2. Dada a maior participação dos trabalhadores no total da população, a fração de ativos em posse deste grupo de indivíduos também aumenta, conduzindo a uma redução na fração da riqueza que pertence aos aposentados, $\lambda$. Visto que os trabalhadores possuem uma menor propensão a consumir, $\epsilon>1$, o choque no crescimento da população reduz a taxa de consumo e, correspondentemente, aumenta a poupança. Com isso, elevam-se $a$ e $k$, correspondentes à acumulação de ativos e capital.

FIGURA 3

Boom demográfico e impactos econômicos no ciclo de vida
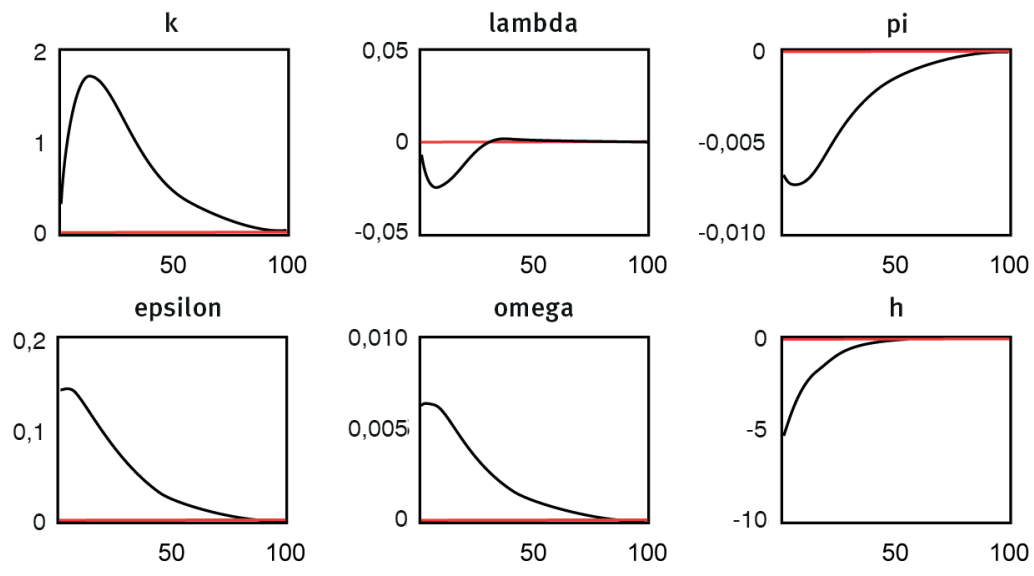

$\mathrm{h}$
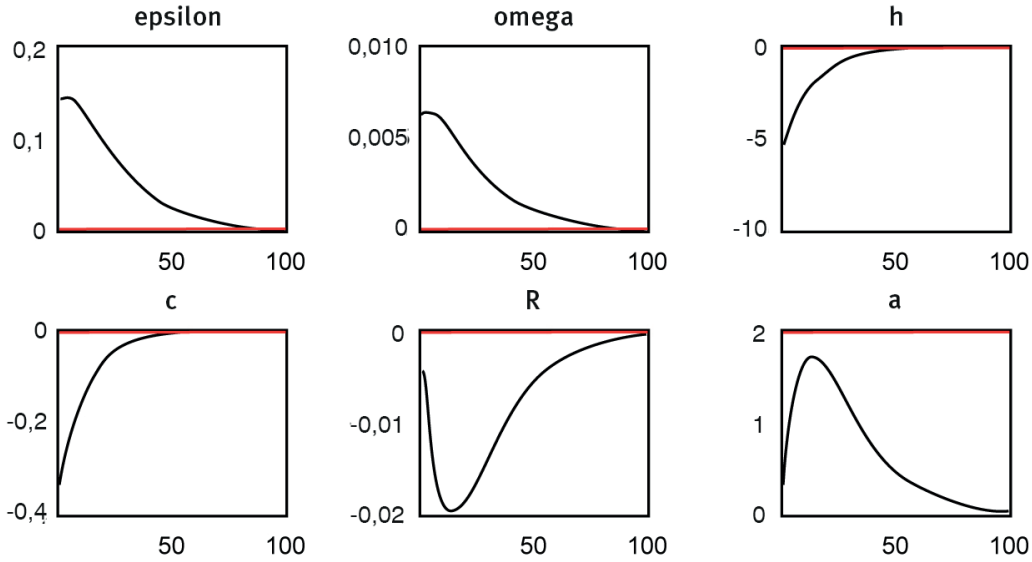

Fonte: Elaboração dos autores. 
O fator de ponderação, $\Omega$, aumenta devido ao crescimento em $\epsilon$ - expressão (11). Mas esse efeito é mais suave do que a redução sofrida pela taxa de juros $R$, reflexo do aumento do estoque da poupança. Desse modo, é reduzido o fator de desconto aplicado à renda do trabalho, $\Omega R$, causando impacto negativo sobre a propensão marginal a consumir dos trabalhadores, $\pi$, e positivo sobre a riqueza humana, $h$. Porém, no caso desta última, o impacto líquido ainda é de diminuição devido à influência direta do choque positivo em $n$.

Esse comportamento na forma de $U$ invertido do capital e o aumento do consumo se alinham aos resultados encontrados por An e Jeon (2006), representando a ampliação da taxa de crescimento do PIB per capita na primeira fase, seguida de queda, à medida que a proporção de trabalhadores é reduzida. Assim, o segundo dividendo demográfico não aparece nessa dinâmica, mas apenas seus impactos para o financiamento da seguridade dos idosos. Já o aumento temporário da parcela de pessoas na fase ativa reduz a relação consumo/produto, aumentando a poupança e acumulação de capital físico e o crescimento econômico. Uma vez dissipado o efeito desse aumento da população ativa, a oferta de trabalho é reduzida e a taxa de crescimento também.

\section{Boom demográfico e políticas de seguridade social}

Nesta seção investigam-se os impactos da demografia sobre as principais variáveis introduzidas pela política fiscal, a citar os benefícios pagos aos aposentados, $S$, as expectativas dos trabalhadores sobre o recebimento futuro, $S^{W}$, e o pagamento de impostos, $t$.

FIGURA 4

Impacto do boom demográfico sobre as variáveis de seguridade social e os impostos
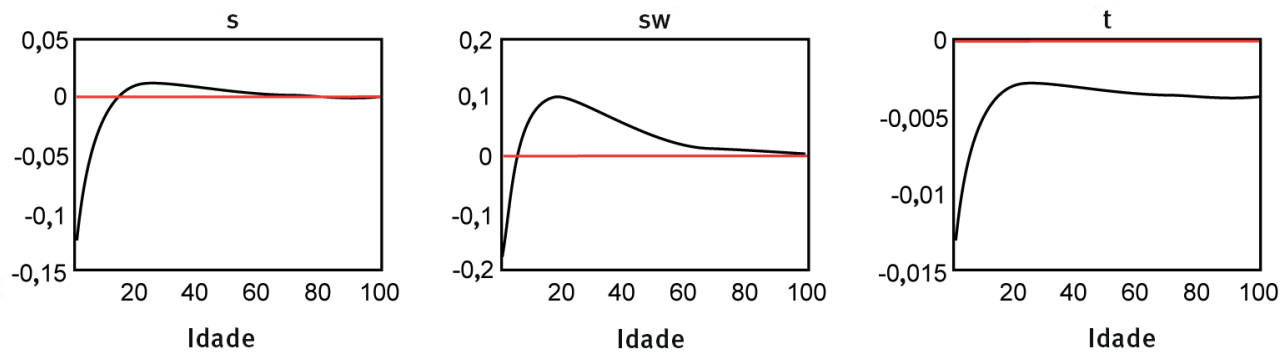

Fonte: Elaboração dos autores.

Simulação de choques exógenos é o principal método de investigação dos efeitos de mudanças em algumas variáveis do modelo sobre demais variáveis e parâmetros. A solução do modelo para o equilíbrio de longo prazo gera os valores estacionários da Tabela 2, para a economia sem governo, e da Tabela 3, com governo. A dinâmica da transição das variáveis associadas à seguridade social em resposta ao choque é mostrada na Figura 4. Em cada um dos três quadros, os valores no eixo vertical são negativos, indicando o impacto negativo do choque positivo na taxa de crescimento populacional, $n$. 
A soma dos benefícios normalizada pelo produto, $S / Y$, é dada pela expressão (B.11) no Anexo $B$ e sua trajetória em resposta ao bônus demográfico, no primeiro quadro à esquerda, na Figura 4. Em cada um dos três quadros da Figura 4, os valores no eixo vertical são negativos, indicando o impacto negativo do choque positivo na taxa de crescimento populacional, $n$.

Verifica-se que o bônus demográfico leva a uma redução provisória do grau de transferências para os aposentados, $s$, nos benefícios esperados pelos trabalhadores, $s^{w}$, e na taxa de tributação, $t$. Os benefícios esperados sofrem o maior impacto porque o impacto da mudança em $n$ é suavizado pelo maior fator de desconto na expressão (B.4) em relação ao desconto na expressão (B.5), dos aposentados.

0 impacto do choque em $n$ sobre a tributação também é negativo (Figura 4). A redução dos benefícios diminui a necessidade de arrecadação e, além disso, do mesmo modo que na economia sem governo, o choque em $n$ reduz a taxa de juros, $R$, na expressão B.10.

\section{Discussão}

Os resultados do modelo teórico e das simulações apresentadas na seção anterior ilustram os impactos de um bônus demográfico em termos de política fiscal e sugerem que o bônus demográfico permite um afrouxamento temporário das pressões orçamentárias do governo. Embora o modelo teórico se limite a assumir que a oferta de trabalho seja inelástica, esses resultados estão de acordo com a intuição econômica para o impacto de um boom demográfico. As simulações indicam redução da necessidade de arrecadação tributária para financiar os pagamentos da seguridade social porque uma maior população economicamente ativa gera maior volume de produto, que é a base de arrecadação.

Simulando choques nas variáveis de política fiscal num contexto de população estável, elucidam-se os efeitos de aumento da emissão de títulos públicos e dos auxílios da seguridade sobre a economia. Efeitos desse tipo de choques no presente modelo são ilustrados pelas Figuras 5 e 6, em um choque que perdura dez períodos. ${ }^{6}$ Como esperado, ambas políticas - aumento da emissão de títulos públicos e aumento dos auxílios da seguridade social - têm efeito negativo sobre o estoque de capital, uma vez que estimulam o consumo.

A intuição econômica do resultado apresentado na Figura 5 está associada às preferências dos agentes enquanto consumidores, que, supostamente, suavizam o consumo ao longo da vida. 0 aumento dos pagamentos de seguridade social eleva o consumo tanto dos aposentados - o pagamento dos benefícios compõe a riqueza dos aposentados - quanto dos trabalhadores, uma vez que a riqueza destes inclui a expectativa de pagamentos de seguridade no futuro. Desse modo, aumento de consumo resulta em menor acumulação de ativos e, portanto, redução do estoque de capital físico da economia, $k$. A propensão marginal a consumir dos aposentados, $\varepsilon$, aumenta porque não se considera a possibilidade

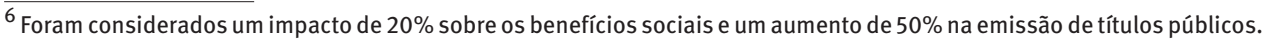


de deixar heranças. Os parâmetros $\varepsilon$ e $\Omega$ seguem a mesma trajetória de reação ao choque positivo no pagamento de seguridade porque a diferença entre eles, conforme a expressão (11), é dada por $\omega$ - probabilidade de passar da fase ativa para aposentadoria -que é fixa.

FIGURA 5

Choque nas transferências da seguridade aos aposentados

k

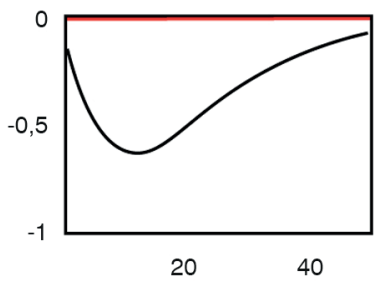

epsilon

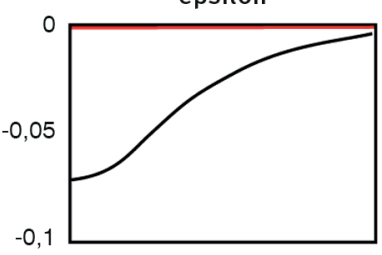

40

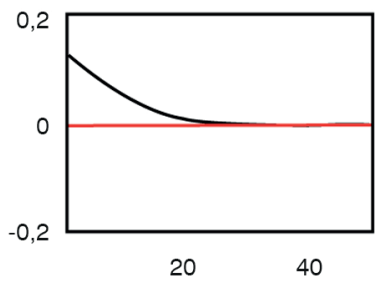

lambda

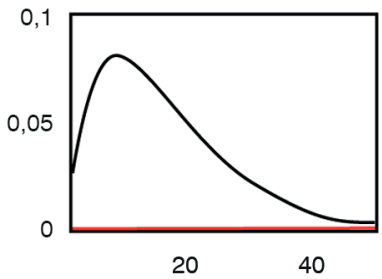

omega

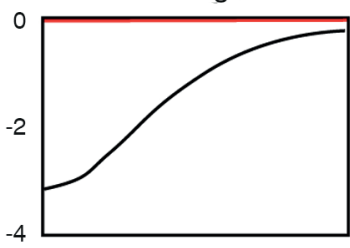

40

$\mathbf{R}$

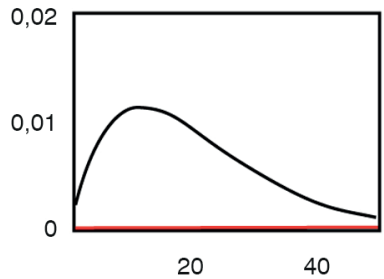

pi

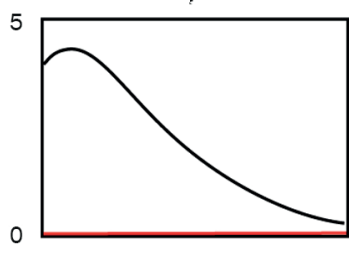

40

$\mathrm{h}$

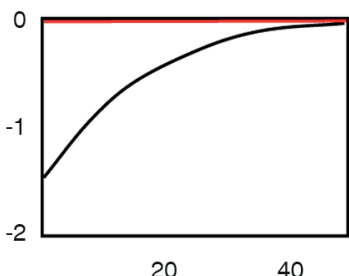

a

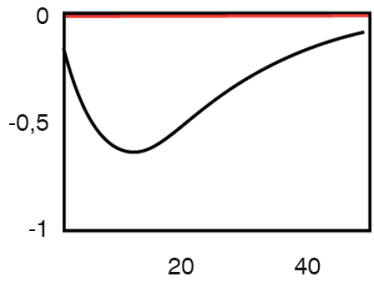

Fonte: Elaboração dos autores.

A riqueza humana $h$ tem uma reação negativa ao choque porque corresponde ao valor presente descontado do fluxo de renda do trabalho. 0 aumento da taxa de juros $R$ e do fator de desconto impacta negativamente esse valor presente descontado. Ainda assim, o consumo agregado da economia, $c$, aumenta porque somam-se as reações positivas do consumo dos trabalhadores ao suavizarem o consumo quando esperam receber os benefícios na vida inativa e o aumento do consumo dos aposentados, em reação ao maior pagamento de seguridade. Assim como o consumo aumenta, a formação de poupança - ou acúmulo de capital financeiro, $a$, se reduz. 
FIGURA 6

Choque na emissão de títulos do governo

k

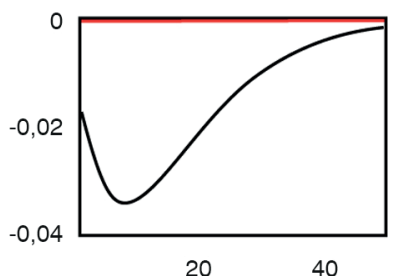

epsilon
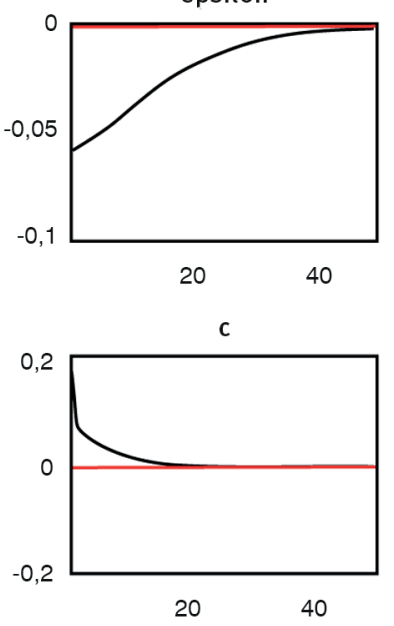

lambda

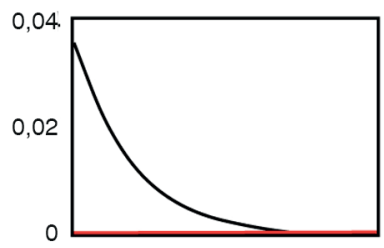

20

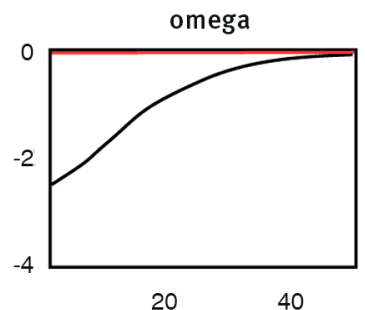

$\mathbf{R}$

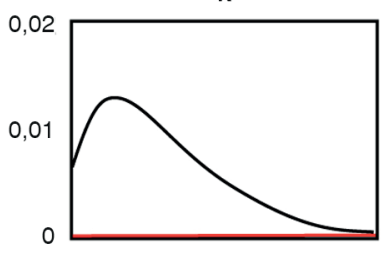

20

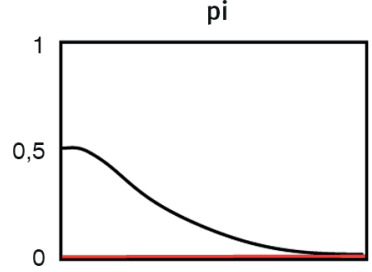

20

40

$\mathrm{h}$

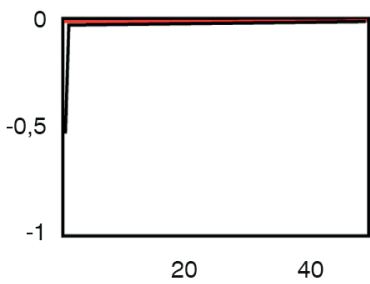

a

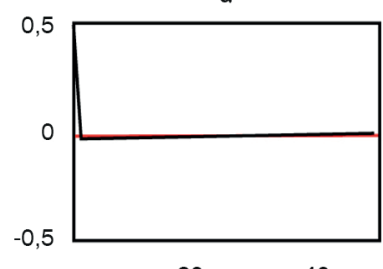

40

Fonte: Elaboração dos autores.

Em resposta ao aumento da emissão de títulos, contrariamente ao crescimento dos pagamentos de seguridade social, ocorre um efêmero aumento de ativos, $a$. A intuição econômica por trás desse aumento é a maior necessidade imposta à economia de financiar maior volume de dívida pública. Em termos qualitativos, o aumento da emissão de dívida tem os mesmos impactos que o crescimento dos pagamentos de seguridade social quando se trata da redução do estoque de capital físico, elevação do consumo, crescimento da taxa de juros e distribuição dos ativos monetários mais favorável aos aposentados - aumento de $\lambda$. Enquanto a seguridade social aumenta diretamente os benefícios recebidos pelos aposentados, a emissão de títulos de dívida pública posterga a arrecadação de impostos que recaem sobre os trabalhadores. Como os consumidores não são ricardianos, reagem com elevação do consumo.

Porém, em termos quantitativos, o impacto do aumento da emissão de dívida é mais suave do que o impacto do crescimento dos pagamentos de seguridade social. Isso porque o impacto sobre o consumo é indireto, ocorrendo por meio da riqueza humana, $H$, ao passo que o pagamento de seguridade afeta o consumo tanto direta quanto indiretamente 
- expressão (34). 0 impacto da emissão de títulos do governo sobre o estoque de capital ocorre a partir da riqueza humana $H_{T}$ e do consumo e tem grandeza mais de dez vezes inferior ao efeito do aumento das transferências sociais.

Uma vez que o bônus demográfico resulta numa redução da taxa de juros e diminuição da necessidade de tributação para financiar os pagamentos de seguridade, pode-se intuir, então, que essa fase da demografia permite um afrouxamento da restrição orçamentária do governo. Quando se trata das contas públicas, a prudência indica que os governos devem aproveitar fases economicamente favoráveis, gerando superávits para enfrentar as fases desfavoráveis.

Os resultados do modelo teórico aqui proposto implicam que as políticas de seguridade social reduzem a poupança porque aumentam o consumo, já no período de vida ativa dos agentes que habitam uma economia do ciclo de vida. Ocorre, portanto, o efeito deslocamento, do capital para o consumo e redução da capacidade de crescimento econômico.

Notamos que o modelo teórico aqui utilizado é de concorrência total nos mercados de produto e de trabalho, não contemplando imperfeições de mercado, tais como concorrência monopolística, informação assimétrica e consequente viscosidade de preços e salários. No entanto, mesmo em modelos teóricos do tipo novo keynesiano, em que tais imperfeições estão presentes, os resultados de longo prazo permanecem os mesmos destes aqui observados a partir do presente arcabouço teórico.

Embora não esteja no escopo deste artigo, isso ocorre especialmente quando a seguridade social é financiada por meio do sistema de repartição simples (pay-as-you-go). ${ }^{7}$ No entanto, tanto os países do sudeste asiático e Japão quanto, por exemplo, os Estados Unidos convivem com esse sistema de financiamento previdenciário e, mesmo assim, experimentaram os benefícios do segundo dividendo demográfico. Camarano e Pesinato (2007) destacam as dificuldades quanto ao financiamento da seguridade social. Já Carneiro et al. (2013) preocupam-se com o impacto do envelhecimento sobre os gastos com saúde assistencial pública e privada, enquanto Zanon, Moretto e Rodrigues (2013) sugerem que uma proporção maior de pessoas idosas deve induzir a mudanças no padrão de consumo de um país ao longo do tempo.

Uma limitação do modelo teórico aqui utilizado é ausência do setor externo e os correspondentes impactos do fluxo internacional de capitais sobre a capacidade de poupança e investimento. No entanto, esses impactos não excluem os resultados em termos da economia doméstica. Além disso, formulações que incluem o setor externo são mais úteis para analisar os impactos de diferenças demográficas sobre o saldo comercial das respectivas economias. Em termos da análise de política fiscal, Ferrero (2005), por exemplo, ressalta

\footnotetext{
$\overline{7}$ No sistema de repartição os recursos financeiros são transferidos diretamente das fontes para os pagamentos dos benefícios previdenciários. A contribuição previdenciária dos indivíduos em período ativo financia os pagamentos de benefícios previdenciários aos indivíduos inativos, ou seja, cada geração custeia os benefícios da geração anterior. Por exemplo, Feldstein (1996) analisa dados de 1930-1992 para os EUA e reconfirma seu estudo anterior de que os indivíduos substituem os benefícios da seguridade social pela poupança pessoal: cada dólar da seguridade social reduz a poupança privada de dois a três centavos. No total a seguridade social reduz a poupança privada em quase $60 \%$.
} 
que o crescimento populacional implica resultados teóricos consistentes com a observação empírica de que aumentos do déficit orçamentário estão associados a aumentos de déficit comercial e vice versa.

Em termos dos resultados do presente artigo, como, então, se relacionam as transformações na estrutura etária brasileira com o desempenho econômico do país ao longo das últimas décadas? 0 boom demográfico simulado na seção anterior resulta num afrouxamento da restrição orçamentária do governo, com respeito à necessidade de arrecadação para financiar as transferências de seguridade aos aposentados. Mas, no caso da economia brasileira, a literatura tem apontado que o segundo dividendo demográfico não foi plenamente aproveitado devido ao fraco desempenho da economia, especialmente durante a década de 1990, que rebateu no mercado de trabalho com grande aumento da informalidade, conforme, por exemplo, Alves (2020).

No mesmo período em que a informalidade aumentava, a geração que esteve na fase economicamente ativa e contribuiu para a previdência social nos anos 1970 - fase de maiores taxas de crescimento econômico brasileiro - entrava na fase de aposentadoria. Esse descompasso é uma das causas do crescimento do déficit no orçamento da previdência social a partir da década de 1990.

Ao longo das mesmas décadas em que o desempenho econômico sofria com a crise da dívida externa e depois com a precarização do mercado de trabalho, ocorria também a mudança no perfil de gênero da força de trabalho - entre 1973 e 2007, a população feminina na PEA passou de $29 \%$ para $40 \%$ (BRUSCHINI; LOMBARDI, 2007) e, em termos de Brasil, em 2001, as mulheres representavam 56,3\% do total de alunos matriculados e $62,4 \%$ do total de alunos que concluíram o ensino universitário, conforme citado por Leta (2003). Desse modo, o reforço dado pelo bônus demográfico feminino ocorreu no Brasil do mesmo modo que nos países da OCDE e sudeste asiático.

Do ponto de vista das contas públicas, as altas taxas de juros e desempenho ruim da economia também implicavam aumento do déficit público operacional durante os anos 1990. Tal conjuntura econômica do mercado de trabalho se reverteu a partir da década de 2000. A partir de 2004 a economia brasileira foi favorecida pela estabilidade interna de preços e pelo bom desempenho da balança comercial devido ao boom das commodities impulsionado pelo crescimento chinês. Nesse período, a expansão da economia brasileira favoreceu o mercado de trabalho e mesmo as contas públicas - já que a arrecadação tributária é função positiva da atividade econômica - que apresentou superávit primário de 2003 até 2014.

No entanto, a existência do segundo bônus depende fortemente do avanço na acumulação de capital humano enquanto ocorre a terceira fase das transformações econômicas e etárias a que se referem Ito e Rose (2010). Famílias com menor número de filhos podem investir mais em educação. Mesmo assim, no caso das economias do sudeste asiático, parte da literatura apresentava receios de que o segundo bônus demográfico fosse totalmente anulado pelo rápido envelhecimento populacional, que, aumentando a razão de dependência, acarretaria na desaceleração do crescimento econômico daqueles países, 
conforme, por exemplo, Mason e Kinugasa (2004). Porém, tal previsão não se concretizou e, de fato, o rápido envelhecimento populacional foi acompanhado de intenso aumento do capital humano. Por exemplo, Han e Park (2010) apresentam um amplo estudo comparando nações asiáticas e africanas. Seus resultados indicam que os países com mais rápido envelhecimento populacional também registram maior acúmulo de capital humano. Esses resultados empíricos sobre países asiáticos parecem, de fato, vir a confirmar as proposições dos modelos de crescimento endógeno que explicam a persistência do crescimento econômico - Lucas (1988) e Romer (1993). De fato, a literatura tem apontado que os países asiáticos aproveitaram não só o segundo bônus demográfico, como também estão prestes a usufruir do terceiro bônus - ou "silver dividend" - como apontam, por exemplo, Ogawa et al. (2021).

$\mathrm{Na}$ economia brasileira, a possibilidade de afrouxamento da necessidade de arrecadação tributária para financiar o pagamento de benefícios sociais foi ofuscada pela insuficiência da acumulação de capital humano durante a transição demográfica.

Como aponta, por exemplo, Turra (2018), a consolidação e expansão dos sistemas de educação e saúde no Brasil ocorreram a partir da década de 1980 e o contexto favorável da transição demográfica em curso ajudou, mas não o bastante. Ao mesmo tempo que a possibilidade de taxação mais suave se seguiria ao maior contingente de população ativa, cresciam os gastos obrigatórios com pagamento de benefícios sociais a partir da Constituição de 1988.

0 aumento do capital humano durante a transição demográfica brasileira ocorreu, mas de maneira heterogênea em termos regionais. 0 trabalho empírico de Baerlocher et al. (2019) encontra evidências do segundo dividendo demográfico para cada uma das cinco regiões brasileiras. Cerca de $90 \%$ das diferenças de renda per capita entre as regiões brasileiras foram explicadas pelas diferenças em capital humano, o que potencializa o aumento da produtividade do trabalho e elevação da poupança, que, por sua vez, leva ao crescimento econômico. No entanto, a heterogeneidade regional, aliada às grandes dimensões do país, implica que essa potencialização da produtividade não foi suficiente para transformar o Brasil numa economia madura, demográfica e economicamente. Isso exigiria que a expansão do ensino tivesse sido mais intensa já na década de 1970.

Numa economia do ciclo de vida com baixa renda per capita, parte da população enveIhece sem ter atingido volume de riqueza que garanta a suavização do consumo até o final do período da vida inativa. Por isso, como apontam, por exemplo, Turra et al. (2011), o Brasil apresenta hoje um viés pró-idoso nas políticas públicas. A proporção de transferências de recursos a idosos, em relação a crianças e jovens, está entre as mais altas do mundo.

Assim, para o Brasil parece estar ainda longe a possibilidade de redução das transferências governamentais a idosos, apesar de quase terminada a mudança em sua estrutura etária. 0 terceiro bônus, que produz benefícios econômicos de uma população que envelhece com saúde e maior nível de escolaridade e, portanto, estende sua capacidade produtiva, também deve demorar mais algumas décadas. 


\section{Considerações finais}

Nesse artigo buscou-se avaliar o impacto de choques na taxa de crescimento da população sobre o equilíbrio macroeconômico de longo prazo de uma economia do ciclo de vida, a partir de simulações num modelo de equilíbrio geral dinâmico. A partir do entendimento de que as variáveis demográficas geram impactos no consumo, na poupança e na acumulação de capital, a transição demográfica, fenômeno recente na trajetória populacional mundial, tem sido tema recorrente em análises de desenvolvimento econômico.

Primeiramente, a introdução do governo, na forma de cobrança de impostos, pagamento de transferências e gastos públicos, reduz a poupança e a formação de capital da economia, além de elevar a taxa de juros de equilíbrio da economia. No entanto, as simulações de choques na taxa de crescimento da oferta de trabalhado gera resultados de que a dinâmica demográfica não incita entraves ao acúmulo de capital, sendo que o aumento provisório da parcela de trabalhadores conduz a um crescimento da poupança e à redução da taxa de juros da economia. Portanto, o comportamento do estoque de capital na economia mostrou que a trajetória é em forma de U invertido, tal como já sugerido na literatura.

Com o incremento dos gastos do governo, títulos públicos e seguridade, pode-se perceber que estas três ferramentas mantêm relação direta com o aumento do consumo e a redução do estoque de capital. Os benefícios da seguridade, ao redistribuírem recursos para os aposentados, atuam como verdadeiros estímulos ao consumo, visto que estes indivíduos possuem maior propensão a consumir do que os trabalhadores.

Por fim, cabe destacar que modelos que consideram o ciclo de vida dos agentes, com horizontes temporais finitos de vida, mantêm diferenças quanto aos modelos com horizontes temporais infinitos. Pode-se destacar que os modelos de ciclo de vida consideram que os indivíduos irão suavizar seu consumo durante a vida, esperando que um dia seu tempo de vida irá findar. Por conta disso, os agentes consumirão mais durante as suas vidas e terão um fator de desconto intertemporal diferenciado, em razão da consciência dos agentes acerca da probabilidade de finitude do horizonte de vida para os períodos subsequentes.

\section{Referências}

ALVES, J. E. D. Do nascimento tardio à morte precoce pela Covid-19. Revista Brasileira de Estudos de População. v. 37, p.1-18, 2020.

AN, C.-B.; JEON, S.-H. Demographic change and economic growth: an inverted-u shape relationship. Economics Letters, v. 92, p. 447-454, 2006.

BAERLOCHER, D.; PARENTE, S. L.; RIOS-NETO, E. Economic effects of demographic dividends in Brazilian regions. The Journal of Economics of Aging, v, 14, April 2019.

BLANCHARD, O. Debt, deficits and finite horizons. Journal of Political Economy, v. 93, n. 21, p. 223-247, 1985.

BLOOMN, D.; WILLIAMSON, J. Demographic transitions and economic miracles in emerging Asia. Cambridge, MA: National Bureau of Economic Research, 1997. (Working Paper, n. 6268). 
BRITO, F. O deslocamento da população brasileira para as metrópoles. Estudos Avançados, V. 20, n. 57, p. 221-236, 2006.

BRUSCHINI, C.; LOMBARDI, M. R. Mulheres no mercado de trabalho: grandes números. Séries Históricas - Portal da Fundação Carlos Chagas, 2007.

CARVALHO, J. A. M. de; GARCIA, R. A. O envelhecimento da população brasileira: um enfoque demográfico. Cadernos de Saúde Pública, v. 19, n. 3, p. 725-733, 2003.

COALE, A.; HOOVER, E. População e desenvolvimento econômico. [S.I.]: Ed. Fundo de Cultura, 1958.

CROIX, D. de la; LINDH, T.; MALMBERG, B. Demographic change and economic growth in Sweden: 1750-2050. Journal of Macroeconomics, v. 31, p. 132-148, 2009.

FELDSTEIN, M. Social security, induced retirement, and aggregate capital accumulation: a correction and update. Cambridge, MA: National Bureau of Economic Research, 1980. (Working Paper, n. 579).

FERRERO, A. et al. Demographic trends, fiscal policy and trade deficits. In: ANNUAL MEETING OF THE SOCIETY FOR ECONOMIC DYNAMICS. Proceedings [...]. Budapest, Hungary: SED, 2005.

FOUGERE, M.; MERETTE, M. Population ageing and economic growth in seven OECD countries. Economic Modelling, v. 16, p. 411-427, 2009.

FUJIWARA, I.; TERANISHI, Y. A dynamic new keynesian life-cycle model: societal aging, demographics, and monetary policy. Journal of Economic Dynamics and Control, v. 32, n. 8, p. 2398-2427, 2008.

GALOR, O.; WEIL, D. Population ageing and economic growth in seven OECD countries. Economic Modelling, v. 16, p. 411-427, 2009.

GERTLER, M. Government debt and social security in a life-cycle economy. Carnegie-Rochester Conference Series on Public Policy, v. 50, p. 61-110, 1999.

IBGE - Instituto Brasileiro de Geografia e Estatística. Projeções da População: Brasil 2000-2060. Rio de Janeiro, 2013.

HAN, C. H.; PARK, C. G. Demographic transition, human capital accumulation and economic growth: some evidence from cross-country and Korean microdata. In: ITO, T.; ROSE, A. (ed.). The economic consequences of demographic change in East Asia. University of Chicago Press, 2010. p. 93-124. (Serie East Asia Seminar on Economics, NBER-EASE, v. 19).

ITO, T.; ROSE, A. Introduction. In: ITO, T.; ROSE, A. (ed.). The economic consequences of demographic changes in Asia. University of Chicago Press, 2010. p. 1-15. (Serie East Asia Seminar on Economics, NBER-EASE, v. 19).

LETA, J. As mulheres na ciência brasileira: crescimento, contrastes e um perfil de sucesso. Estudos Avançados, v. 17, n. 49, p. 271-284, 2003.

LUCAS JUNIOR, R. E. On the mechanics of development planning. Journal of Monetary Economics, New York, v. 22, n. 1, p. 3-42, July 1988.

MALTHUS, T. R. Ensaio sobre a população. 2. ed. [S.I.]: Nova Cultural, 1986.

MASON, A. Demographic transition and demographic dividends in development and developing countries. In: UNITED NATIONS EXPERT GROUP MEETING ON SOCIAL AND ECONOMIC IMPLICATIONS OFCHANGING POPULATION AGE STRUCTURES. Proceedings [...]. Mexico City: United Nations, 2005. 
MASON, A.; KINUGASA, T. East Asian economic development: two demographic dividends. Honolulu, Hawaii: East-West Center, June 2005. (East-West Center Working Papers - Economic Series, n. 83).

MASON, A.; LEE, R.; LEE, S. Demographic transition and economic growth in the Pacific rim. In: ITO, T.; ROSE, A. (ed.). The economic consequences of demographic change in East Asia. University of Chicago Press, 2010. p. 19-55. (Serie East Asia Seminar on Economics, NBER-EASE, v. 19).

MOURA, G. V. Multiplicadores fiscais e investimento em infraestrutura. Revista Brasileira de Economia, v. 69, n. 1, p. 75-104, 2015.

NOTESTEIN, F. Economic problems of population change. London: Oxford University Press, 1953.

OGAWA, N.; MANSOR, N.; LEE, S.; ABRIGO, M. R. N.; ARIS, T. Population aging end the three demographic dividends in Asia. Asian Development Review, v. 38, n. 1, March 2021.

PAIVA P. T. A.; WAJNMAN, S. Das causas às consequências econômicas da transição demográfica no Brasil. Revista Brasileira de Estudos de População, v. 22, n. 2, p. 303-322, 2005.

ROMER, P. M. Endogenous technological change. Journal of Political Economy, v. 98, n. 5 , S71-S102, October 1990.

TAFNER, P.; BOTELHO, C.; ERBISTI, R. Transição demográfica e o impacto fiscal na previdência brasileira. In: CAMARANO, A. A. (org.). Novo regime demográfico: uma nova relação entre população e desenvolvimento? Rio de Janeiro: Ipea, 2015.

TAYLOR, A. M. Debt, dependence and the demographic transition, Latin America in to the next century. World Development, v. 23, n. 5, p. 869-879, 1995.

THOMPSON, W. S. Population. Academic Journal of Sociology, v. 34, n. 6, p. 959-975, 1929.

TOURINHO, O. A. F.; CARNEIRO, R. F. Fiscal policy for public debt stabilization in a multiple household dynamic general equilibrium model for Brazil. In: ENCONTRO NACIONAL DE ECONOMIA, 47. Anais [...]. São Paulo: Anpec, 2019. Disponível em: https://en.anpec.org.br/previous-editions. php.

TURRA, C. M.; QUEIROZ, B. Before it's too late: demographic transition, labour supply, and social security problems in Brazil. In: UNITED NATIONS EXPERT GROUP MEETING ON SOCIAL AND ECONOMIC IMPLICATIONS OF CHANGING POPULATION AGE STRUCTURES. Proceedings [...]. Mexico City: United Nations, 2005.

TURRA, C. M.; QUEIROZ, B.; RIOS-NETO, M. E. L. G. Ydyossincrasies of intergenerational transfers in Brazil. In: LEE, R.; MASON, A. (ed.). Population aging and the generational economy: a global perspective. Northampton, MA: Edward Elgar Publishing, 2011. p. 394-407.

TURRA, C. M. Os ajustes inevitáveis da transição demográfica no Brasil. In: VIEGAS, M. Alternativas para uma crise de múltiplas dimensões. Belo Horizonte: Cedeplar/UFMG, 2018.

UN - United Nations. World population prospects: the 2012 revision. New York: United Nations, 2013.

WANG, F.; MASON, A. Demographic dividend and prospects for economic development in China. In: UNITED NATIONS EXPERT GROUP MEETING ON SOCIAL AND ECONOMIC IMPLICATIONS OF CHANGING POPULATION AGE STRUCTURES. Proceedings [...]. Mexico City, 2005.

WEIL, P. Overlapping families of infinitely-lived agents. Journal of Public Economics, v. 38, p. 183-198, 1989. 


\title{
Sobre os autores
}

Henrique Reichert é doutor em economia pela Universidade Federal de Santa Catarina (UFSC). Coordenador geral de apoio às micro e pequenas empresas, na Subsecretaria de Desenvolvimento das Micro e Pequenas Empresas, Empreendedorismo e Artesanato, do Ministério da Economia.

Patricia Bonini ${ }^{8}$ é PhD em Economia pela Universidade de Birmingham, Reino Unido. Professora e pesquisadora no departamento de Ciências Econômicas da Universidade do Estado de Santa Catarina (Udesc).

Carolina Fernandes Custodio é mestranda em Economia no Instituto Brasileiro de Ensino, Desenvolvimento e Pesquisa (IDP) e bacharel em Ciências Econômicas pela Universidade do Estado de Santa Catarina (Udesc). Bolsista voluntária externa no "Grupo de Estudos de Programação Aplicado à Economia” na Udesc e sócia e pesquisadora na Caravela Soluções, empresa especializada em análise de dados e estatísticas.

\section{Endereço para correspondência}

\author{
Henrique Reichert \\ Esplanada dos Ministérios, Ministério da Economia, Bloco J, sala 214, Zona Cívico-Administrativa \\ 70053-900 - Brasília-DF, Brasil \\ Patricia Bonini \\ Universidade do Estado de Santa Catarina (Udesc), Departamento de Ciências Econômicas \\ Av. Madre Benvenuta, 2037, Itacorubi \\ 88035-001 - Florianópolis-SC, Brasil \\ Carolina Fernandes Custodio \\ SHIN CA 05, Bloco G, apto. 308, Lago Norte \\ 71503-505 - Brasília-DF, Brasil
}

\section{Abstract}

Macroeconomic effects of social security in a demographic bonus context: simulating a life cycle model

This paper analyzes the impact of fiscal and social security policies in the presence of demographic bonuses in a dynamic general equilibrium model with life cycle hypothesis. Based on the theoretical framework proposed by Gertler (1999), but allowing a non-stationary demographic structure, the context of the demographic bonus was captured to infer the impact of tax and social security policy on income distribution during the demographic bonus phase. The results of the simulations indicate that the temporary increase in the share of workers in the population generates an increase in savings and a reduction in interest rates, while the behavior of the capital stock in the economy showed that the trajectory is an inverted $U$ shape, as already suggested in the literature. In addition, it was seen that policies increasing the degree of social security contribution are tools to stimulate consumption and income redistribution in favor of retirees. The contribution of the paper is the analysis of macroeconomics implications of a demographic dividend with investment and fully microfounded consumption decisions.

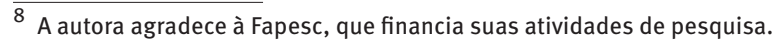


Keywords: Demographic transition. Demographic shocks. Social security. Life cycle model.

\section{Resumen}

Efectos macroeconómicos de la seguridad social en un contexto de bonos demográfico: simulación de un modelo de ciclo de vida

Este artículo analiza el impacto de la política fiscal y previsional ante la presencia de bonos demográficos en un modelo dinámico de equilibrio general con agentes comportándose según la hipótesis del ciclo de vida. Con base en el marco teórico propuesto por Gertler (1999), pero permitiendo una estructura demográfica no estacionaria, se capturó el contexto del bono demográfico para inferir sobre el impacto de la política fiscal y previsional sobre la distribución del ingreso durante la fase del bono demográfico. Los resultados de las simulaciones indican que el aumento temporal de la participación de los trabajadores en la población genera un aumento del ahorro y una reducción de las tasas de interés, mientras que el comportamiento del stock de capital en la economía mostró que la trayectoria es en forma de U invertida, como ya se ha sugerido en la literatura. Además, se observó que las políticas que aumentan el grado de cotización a la seguridad social son herramientas para estimular el consumo y la redistribución del ingreso a favor de los jubilados.

Palabras clave: Transición demográfica. Bonos demográficos. Seguridad social. Modelo de ciclo de vida. 


\section{ANEXO A}

Definição das equações de estado estacionário: economia fechada e sem governo, conforme Gertler (1990)

No estado estacionário, $N_{t} X_{t}$ cresce à taxa $(1+\chi)(1+n) \approx(1+\chi+n)$. Devido a esse crescimento de longo prazo, a definição de níveis estacionários das variáveis endógenas do modelo deve ser feita em termos de níveis relativos ao produto: $k_{t}=\frac{K_{t}}{Y_{t}}, h_{t}=\frac{H_{t}}{Y_{t}}, a_{t}=\frac{A_{t}}{Y_{t}} \mathrm{e}$ $c_{t}=\frac{C_{t}}{Y_{t}}$. De modo facultativo, pode-se incluir a relação entre aposentados e trabalhadores, $\psi$, como uma décima variável do modelo, com o intuito apenas de verificar sua dinâmica, dado um choque no crescimento populacional. Assim, o modelo pode ser descrito como: $k(x+n+\delta)=1-\pi[(1+(\varepsilon-1) \lambda) R k+h]$

$\lambda=\psi \frac{(1+n-\gamma)}{1+p-\gamma \omega(R \beta)^{\sigma}}$

$\pi=1-(R \Omega)^{\sigma-1} \beta^{\sigma}$

$\varepsilon \pi=1-\left(R^{\sigma-1} \beta^{\sigma} \gamma\right)$

$\Omega=\omega+(1-\omega) \in^{\frac{1}{1-\sigma}}$

$R=\frac{1-\alpha}{k}+(1-\delta)$

Sendo que $H(R, \Omega)=\frac{R-(1+p)}{R-(1+x) \frac{\omega}{\Omega}}$ corresponde à relação entre a riqueza humana de uma economia com agentes de horizonte infinito de maximização de utilidade e a riqueza humana quando os agentes seguem a hipótese de ciclo de vida. Nesta última a taxa de desconto intertemporal inclui o termo de ponderação, $\Omega$. A solução para a riqueza relativa à renda, $\frac{H_{t}}{Y_{t}^{t}}$ :

$h=H(R, \Omega) \frac{R \alpha}{R-(1+p)}$

$a=k$

\section{ANEXO B}

Definição das equações de estado estacionário com variáveis de política fiscal e de seguridade, conforme Gertler (1990)

Similarmente à economia sem governo, os níveis de estado estacionário da economia com governo serão definidos em termos de taxa em relação ao produto. Especificamente, para as três variáveis: $t=T / Y, s=S / Y$ e $s^{w}=s^{w} / Y$. Adicionalmente, $\bar{g}_{t}, \bar{b}_{t}$ e $\bar{e}_{t}$ serão fixas. Por fim, as expressões para $\pi_{t}, \epsilon_{t}$ e $R$ são as mesmas da economia sem governo. 
Então, o equilíbrio de longo prazo do modelo que inclui o governo se define como:

$$
\begin{aligned}
& k(p+\delta)=1-\left[(k+\bar{b})(1-\lambda) R+h+s^{w}+\varepsilon[(k+\bar{b}) \lambda R+s]\right]-\bar{g} \\
& \lambda=\psi+\frac{\omega(\bar{e}-\varepsilon \pi s)(k+b)^{-1}}{1+n-\gamma} \frac{(1+n-\gamma)}{(1+x+n)-\gamma \omega(R \beta) \sigma} \\
& t=[R(1+x+n)] \bar{b}+\bar{g}+\bar{e} \\
& s^{w}=H(R, \Omega) \frac{(s / \psi) \varepsilon(1-\omega)}{\Omega(R-(1+x+n))} \\
& s=\bar{e} \frac{R}{R-\gamma(1+x)}
\end{aligned}
$$

Para a riqueza humana, no caso da economia com governo:

$$
h=H(R, \Omega) \frac{R(\alpha-\tau)}{R-(1+\chi+n)}
$$

Podendo ser substituída a expressão (B.3) para a taxa de imposto, $t$ :

$$
h=H(R, \Omega)\left(\frac{R(a-\bar{g}-\bar{e})}{R-(1+x+n)}-R b\right)
$$

